\title{
DIMENSIONES PARA PENSAR EL JUEGO COMO PRÁCTICA SALUDABLE Y DERECHO DE LA INFANCIA
}

Dimensions for thinking the game as healthy practice and children's right

Dimensões a pensar sobre o jogo como prática saudável e direito de infância

\section{Ivana Verónica Rivero}

Universidad Nacional de Río Cuarto, Argentina. Telf.: 0358-4676377. Correo electrónico: ivrivero13@gmail.com

\section{Resumen}

Argentina adhiere a la Convención de los Derechos de los Niños, de modo que, en este territorio, el juego es dicho un derecho de las niñas y niños. En tanto, actividad mimética con compromiso corporal, asociada al esparcimiento, y a la vida cultural, el juego aporta al bienestar de las personas. Se hace presente en propuestas educativas y/o recreativas con diferentes grados de formalidad (sistema educativo formal, clubes, vecinales, centros comunitarios, merenderos) en atención a diferentes poblaciones (escolares, preescolares, adultos mayores, discapacidad). Incluso, algunos organismos no gubernamentales ocupados en diseñar modos de intervención efectiva en atención a necesidades sociales, incluyen al juego en su misión.

El escrito que aquí se comparte surgió a solicitud de una fundación argentina (con presencia en Chile y Brasil) que atiende a problemáticas de la infancia. Es por ello que el planteo de la temática se lleva al plano de esta franja etaria, aun cuando su potencia la excede, y toma como referencia la Convención de los Derechos del Niño.

Se abordan las dimensiones ética, estética y política como facetas del juego que, sin desconocer otras posibles, permiten hacer foco en tensiones que se generan en el ámbito de las relaciones interpersonales entre la historia y la posibilidad de cambio (ética), entre el participar de un juego y el decirse jugando (estética), y las condiciones físico ambientales y simbólicas en que el juego acontece (política).

Palabras clave: juego, derecho, ética, estética, política. 


\begin{abstract}
Argentina adheres to the Convention on the Rights of Children, so that, in this territory, gambling is a right of children. In as much, mimetic activity with corporal commitment, associated to the recreation, and to the cultural life, the game contributes to the welfare of the people. It is present in educational and / or recreational proposals with different degrees of formality (formal education system, clubs, neighborhoods, community centers, snack bars) in attention to different populations (schoolchildren, preschoolers, seniors, disability). Even some non-governmental organizations engaged in designing effective intervention modes in response to social needs, include the game in its mission.

The document that is shared here arose at the request of an Argentine foundation (with presence in Chile and Brazil) that deals with problems of childhood. That is why the approach of the issue is taken to the plane of this age group, even when its power exceeds it, and takes as reference the Convention on the Rights of the Child.

The ethical, aesthetic and political dimensions are addressed as facets of the game that, without ignoring other possible ones, allow us to focus on tensions generated in the field of interpersonal relations between history and the possibility of change (ethics), between to participate in a game and to say itself playing (aesthetics), and the physical and symbolic environmental conditions in which the game takes place (politics).
\end{abstract}

Keywords: game, law, ethics, aesthetics, politics.

\title{
Resumo
}

A Argentina adere à Convenção sobre os Direitos da Criança, de modo que, neste território, o jogo é um direito de crianças. Em tanto, a atividade mimética com o compromisso corporal, associada à recreação e à vida cultural, o jogo contribui para o bem-estar das pessoas. Está presente em propostas educacionais e / ou recreativas com diferentes graus de formalidade (sistema de educação formal, clubes, bairros, centros comunitários, lanchas) em atenção a diferentes populações (escolares, pré-escolares, idosos, deficiência). Mesmo 
algumas organizações não governamentais envolvidas na concepção de modos de intervenção eficazes em resposta a necessidades sociais, incluem o jogo em sua missão.

O documento que é compartilhado aqui surgiu a pedido de uma fundação argentina (com presença no Chile e no Brasil) que trata dos problemas da infância. É por isso que a abordagem da questão é levada ao plano dessa faixa etária, mesmo quando o poder excede, e toma como referência a Convenção sobre os Direitos da Criança.

As dimensões ética, estética e política são abordadas como facetas do jogo que, sem ignorar outras possíveis, nos permitem focar tensões geradas na esfera das relações interpessoais entre a história e a possibilidade de mudança (ética), entre as participar de um jogo e dizerse tocar (estética) e as condições ambientais físicas e simbólicas nas quais o jogo ocorre (política).

Palavras-chave: jogo, direito, ética, estética, política.

\section{El juego: derecho de las niñas y niños}

Desde comienzos del siglo pasado las Naciones Unidas reconocen derechos iguales a todos los miembros de la familia humana, y derecho a cuidados y asistencia especiales a la infancia.

La necesidad de proporcionar protección especial a las niñas y niños ha sido enunciada desde 1924 en distintos documentos internacionales, en estatutos y escritos de organismos especializados y organizaciones internacionales que se interesan en el bienestar del niño ${ }^{1}$.

Es recién en 1989 cuando se declara la Convención de los Derechos del Niño, un documento internacional que reúne cincuenta y cuatro artículos organizados en tres partes, y que se expide respecto de los aspectos a resguardar, la difusión y la implementación de los derechos enunciados.

\footnotetext{
${ }^{1}$ Entre ellos, la Declaración de Ginebra de 1924 sobre los Derechos del Niño, Declaración de los Derechos del Niño adoptada por la Asamblea General el 20 de noviembre de 1959, Declaración Universal de Derechos Humanos, Pacto Internacional de Derechos Civiles y Políticos (en particular, en los artículos 23 y 24), Pacto Internacional de Derechos Económicos, Sociales y Culturales (en particular, en el artículo 10).
} 
En la robusta primera parte de dicha Convención se pueden advertir que las Naciones Unidas acuerdan para las niñas y niños el derecho a la vida, a un nombre, a conocer a sus padres, ser cuidado por ellos, derecho a ser preservada su identidad, a expresarse libremente y a tener la oportunidad de ser escuchado; derecho al acceso a información que tengan por finalidad promover su bienestar; derecho a la libertad de pensamiento, conciencia y religión guiada por sus padres. La Convención también reconoce protección de la ley contra ataques a su honra y reputación, protección contra todo tipo de perjuicio o abuso, descuido o trato negligente; contra la explotación económica y el uso de estupefacientes; impide el secuestro, la venta o trata de niños. Las niñas y niños tienen derecho a instituciones, instalaciones y servicios para su cuidado; derecho a disfrutar de una vida plena y decente; derecho a la salud, a la seguridad social, a un nivel de vida adecuado para su desarrollo; derecho a la educación, a tener su propia vida cultural aun cuando pertenezca a un grupo minoritario.

El artículo 31 de dicha Convención reconoce "el derecho del niño al descanso y el esparcimiento, al juego y a las actividades recreativas propias de su edad y a participar libremente en la vida cultural y en las artes”. Es así que a partir de 1989 el juego comienza a ser dicho un derecho de la infancia formalmente asociado al descanso, al esparcimiento, a la recreación, a la vida cultural y artística ${ }^{2}$. Esta asociación rescata la potencia y arrastre cultural del juego como aporte al bienestar de las niñas y niños.

Pensar en niñas y niños $\operatorname{sanos}^{3}$ implica, según Restrepo (en Restrepo y Málaga, 2001), no sólo satisfacer sus necesidades básicas (es decir, tener donde vivir, qué comer, donde acudir si se está enfermo y trabajo remunerado), sino también garantizar aspiraciones que todo ser humano y grupo desea poseer, por ejemplo, derechos humanos, paz, justicia, llevar una vida digna, calidad de esa vida, posibilidad de crear, de innovar, de sentir placer, de tener acceso al arte y a la cultura. Es precisamente la atención al derecho a esas otras aspiraciones ligadas al completo bienestar de las personas, las que justificarían el

\footnotetext{
${ }^{2}$ El juego comienza a ser dicho derecho de la infancia en la Declaración de los Derechos del Niño de 1959, que proclama que "(el) niño debe disfrutar plenamente de juegos y recreaciones (...); la sociedad y las autoridades públicas se esforzarán por promover el goce de este derecho" (Principio 7).

${ }^{3}$ La Organización Mundial de la Salud entiende que "la salud es un estado de completo bienestar físico, mental y social, y no solamente la ausencia de afecciones o enfermedades" (1946).
} 
ingreso del juego en la agenda de las preocupaciones gubernamentales. El reconocimiento de su maleabilidad para ser utilizado como un recurso educativo (porque jugando el niño aprehende el mundo físico y social, porque ensaya, practica, aprende contenidos de distinto orden) refuerza ese ingreso.

Este es un escrito sobre el juego, en el que convergen tres grandes universos de significado: educación, salud y derecho, tres universos en apariencia inconexos (cuyo análisis detenido excede en sobra la intención y las posibilidades de este documento) que destellan esporádicamente a fin de ir tejiendo una red contenedora para acciones concretas por, con y para niñas y niños de distintos países, envueltos en realidades diferentes, pero que comparten la potencialidad del futuro.

\section{Juego, jugar, juguete}

Aun cuando diferentes campos de conocimiento puedan reconocer en él un escenario predilecto para la expresión de múltiples objetos (aprehensión del mundo, canalización de tensiones, preparación para la vida, etc), el juego es un universal cultural que produce cultura (Huizinga, 2000) que se caracteriza por ser una ocupación de tiempo libre, con compromiso corporal, de tensión agradable (Elías y Dunning, 1992) con sesgo autotélico (Pavía, 2006); una acción colectiva (Naishtat, 2005) construida y (re) significada por el contexto social y cultural (Scheines, 1998).

El encontrarse con otros niñas y niños, el tener la posibilidad de estar ahí juntos esperando una ocurrencia para ocupar el tiempo, la decisión de acordar reglas para construir una situación que permita percibir la propia capacidad de correr, saltar, rodar por pilas de arena, hacer barro, trepar en los árboles, acostarse en el pasto a mirar el cielo, probar, ensayar, entretenerse, son actividades miméticas, autotélicas, con fin en sí mismas que hacen su aporte al bienestar de las niñas y los niños, ubica a las niñas y niños en el entramado bio-social que los habilita a entender el mundo, su mundo, el que le toca transitar, los habilita a entenderse entre sí (Wittgenstein, 2004).

La oportunidad de crear (acciones, decisiones) y, al mismo tiempo, reforzar (lo sabido, conocido), sumado al desconocimiento del resultado de los acontecimientos, hacen 
del juego una ocupación gustosa del tiempo disponible. El juego es una ocupación en tiempo de recreo y para recreo, un paréntesis en la vida cotidiana, en que los jugadores se entre-tienen, se tienen entre la diversión y el aburrimiento, entre el entusiasmo y el desgano, entre la esfera temporera creada en el juego y la vida cotidiana. El juego se sostiene en la incertidumbre (Caillois, 1994), en la intensidad, en la tensión (Huizinga, 2000), entre la regla y la libertad, entre las acciones que el grupo de juego espera, aprueba, acostumbra (que deja expuesto el arrastre cultural), y las acciones que el mismo grupo considera nuevas, transgresoras, sorprendentes (que transparenta la potencia cultural).

Ningún medio de comunicación puede reemplazar la potencia de estar con otros, de jugar juegos que cansen, que hagan pensar, que habiliten desafíos, que necesiten del canto o del relato, juegos al aire libre que expongan a los jugadores a los cambios de la naturaleza (el viento, el sol, la sombra, el frío, el calor), juegos con elementos naturales (agua, tierra, ramitas, piedras), en relación a otros seres vivos (árboles, animales); juegos al aire libre que les permita percibir la diferencia entre respirar aire saturado (smock, de encierro) y aire oxigenado, entre estar en un lugar inerte con temperatura estable, luz artificial y entretenimientos estáticos e individuales (condición idealmente encontrada en los shoppings), y estar en un lugar sujeto a las condiciones del clima, teniendo como techo el cielo, donde se propicie el encuentro con otros niños y el movimiento corporal compartido. En el juego la presencialidad deviene innegociable, la potencia del jugar está en el relato en primera persona (del singular y del plural) en los contextos particulares en que acontecen. Se pueden identificar que cuando de infancia se trata, el concepto juego es utilizado para referir a los juegos, a los juguetes y al jugar (emparentado con la actitud).

\section{a. El juego como actividad: los juegos}

Los juegos tienen la característica de ser actividades que acontecen en razón de la satisfacción que produce su misma práctica. Actividades libres, organizadas, que poseen tendencia propia, cuyo curso y sentido se agota y renueva constantemente (Huizinga, 2000), actividad a la que principalmente (pero no exclusivamente) las niñas y niños dedican la mayor parte de su tiempo. 
Entender el juego como una actividad implica pensar en un conjunto de tareas en las que late la demanda de un hacer esperado que posibilita y restringe, al mismo tiempo, las decisiones de los participantes. Actividad que, por el movimiento de los jugadores, por el espacio, por la disposición de los elementos, puede ser reconocida a simple vista como un juego. De aquí que se expresa en lo que Pavía llama 'forma del juego', es decir, en "la apariencia singular, de un juego específico. Su configuración general” (2006: 41). En esta dirección, los juegos sencillos y complejos, populares y deportivos, los juegos intelectuales, juegos de y con movimiento, juegos de competencia y cooperativos, juegos de construcción, juegos de azar, vértigo, representación o mímica, juegos de emulación, juegos suaves y violentos, bullicioso y tranquilos, juegos de ronda, de persecución, de tablero, con pelotas, juegos individuales, juegos con otros.

Sin embargo, el participar de una actividad que puede ser reconocida externamente como un juego no es igual a 'estar jugando'. Esta contradicción exhibe la definición del juego como ‘acción’ (Huizinga, 2000: 20).

\section{b. El juego como acción: el jugar}

Participar de una actividad que puede ser reconocida externamente como juego no es igual a estar jugando. El juego en tanto acción (Huizinga, 2000), el 'jugar' (Mantilla, 2001), 'lúdico' (Mandoki, 2006), implica disponerse a entender lo que se hace y se dice como un juego.

Lo lúdico remite a una 'actitud' (Huizinga, 2000:250); a una 'manera de jugar' (Caillois, 1958: 20) en la que el proceso es más importante que el producto. Lo lúdico es un 'modo de jugar' (Pavía, 2006: 42), es decir, a la manera particular de acoplase al juego. El modo se emparenta con la actitud, "donde confluyen componentes cognitivos y afectivos amalgamados, parafraseando a Bourdieu, por el habitus de los sujetos según el contexto social que los configurar" (2010: 68).

Ese momento de disfrute compartido se puede alcanzar participando de una actividad autotélica, es decir, una actividad cuyo fin sea ella misma, su propia realización: en las producciones musicales que espontáneamente ganan espacio en los parques públicos, 
en la creación de imágenes en papeles con témperas y acuarelas puestos a disposición en los paseos de arte, en el vuelo que se alcanza al aceptar la invitación de los cuentacuentos, en las confusiones que generan los payasos, en la ficción que montan los titiriteros detrás del biombo, y en el mundo imaginario al que transportan los mimos con sus gestos y movimientos.

En el juego, lo lúdico remite a su intensidad, a la oportunidad que los participantes encuentran para despegarse de la literalidad, olvidarse ( $\sin$ hacerlo del todo) del día, la hora y las obligaciones para disfrutar lo que surge (intermezzo dirá Huizinga). En el juego, lo lúdico habilita la creatividad, surge de la intención de querer jugar, de querer montar con otros algo que gusta, satisface y entretiene a todos, disfrutar de esa realidad aparente, creer en ella sin olvidar que es de "mentiritas".

Lo lúdico en el juego es una construcción de los participantes que se desmorona al mismo tiempo que se construye, en la que cuerpo y lenguaje se funden para crear sentido (Rivero, 2012). Lo lúdico implica entenderse con otros para crear una nueva versión de lo que se hace y dice.

Así, la posibilidad de jugar, que se amplía al compartir y ensayar situaciones de juego con otros, podría variar de acuerdo al contexto en que acontece. No es lo mismo jugar con otros en la casa de un jugador (igual que no es lo mismo jugar en la propia casa que en la casa de un amigo), en la plaza (donde si bien el espacio es público, su uso no está regulado sino por el sentido común de la comunidad) o en la escuela (donde las acciones están reguladas por un deber hacer ajustado a lo que la sociedad considera deseable y controladas por los adultos encargados de enseñar ese deber).

\section{c. Los juguetes}

Hasta aquí se ha dicho que el juego es una actividad, y una acción, sin embargo, se suelen denominar 'juego' a aquellos artefactos, elementos, aparatos cuyo uso no es unilateral, artefactos que invitan a ser utilizados de distintas formas, aparatos que llaman al movimiento corporal (bicicletas, trepadores), a la exploración (tuneles), al encuentro con 
otros (hamacas, areneros, canchas, pistas), a vivir distintas sensaciones (tobogán, calecita, patines), a hacer algo diferente (rompecabezas, tableros, dados).

Los juegos de la plaza, como trepadores, toboganes, hamacas, sube y bajas, troncos, bancos del parque invitan a moverse para despojarse de la cotidianeidad. Lo mismo ocurre con los espacios verdes y baldíos cuidados (con el pasto corto, regados, libres de todo peligro), las explanadas arboladas, paseos ecológicos, lugares que invitan al descanso y la recreación (como espejos de agua, costaneras, senderos), lugares públicos que permiten disfrutar de estar con otros. Lugares que demandan atención y que los adultos tenemos la responsabilidad de cuidar, acondicionar y mantener para el bienestar de la comunidad.

Lo que ocurre es que el juego no es una actividad como cualquier otra, puede despertar la experiencia estética de lo lúdico, en la cual la principal habilidad demandada es la flexibilidad para desenredarse de las ataduras del mundo cotidiano y crear. Al jugar de un modo lúdico, el lugar, el escenario, los artefactos, los juguetes son cómplices del jugador. Habrá que advertir que existe una trama que se teje entre juguetes, cultura, educación e infancia, el juguete ocupa un lugar en la construcción de lo infantil. "Además de objetos para jugar, los juguetes son productos, objetos de consumo, con todo lo que esto implica en cuanto a estrategias de comercialización... Una empresa fabrica un producto, lo tiene que vender, lo adapta al gusto del consumidor a la vez que va formando el gusto también” (Pellegrinelli en Cursiva, 2010: 46).

\section{Dimensiones para pensar el juego como derecho de la infancia}

En un escrito minucioso editado por Fundación Bernard van Leer, Lester y Rusell (2011) proponen analizar el reconocimiento por parte de los adultos del derecho de los niños al juego a partir de las tres categorías en que suelen agruparse los artículos de la Convención de las Naciones Unidas sobre los Derechos del Niño: derecho a la protección, derecho a la participación y derecho a la provisión (los autores las llaman, las tres 'p’).

A fin de abarcar el universo del juego en la descripción de prácticas cotidianas (tanto acontecidas como planeadas) con niñas y niños de diferentes contextos socioculturales, se avanzará en el intento por describir tres dimensiones, aspectos o facetas 
del juego que se desprenden del análisis de los conceptos propuestos por Lester y Rusell (2011).

Así, a partir de la idea de protección se avanza en el diseño de la dimensión ética del juego, donde se presentan las tensiones entre la seriedad del mundo adulto y su pretensión de formar a las nuevas generaciones (enseñando los saberes que la sociedad reconoce valiosos), y la ludicidad del mundo infantil y su fragilidad para hacer y decir diferente a lo tradicional. Más adelante, se analiza la idea de participación para acceder a la dimensión estética del juego, donde se exhibe la necesidad de correrse de la perspectiva adultocéntrica y, asumiendo el lugar de los jugadores, reconocer las particularidades del jugar. Finalmente, haciendo foco en la provisión se instalan argumentos en favor de la dimensión política del juego, aquella que destaca, por un lado, la relación entre los jugadores y el reconocimiento de líderes democráticos que actúen en beneficio de todos (para el bienestar propio y ajeno), y por otro lado, la disposición, apropiación y mantenimiento del espacio público destinado a jugar con otros como responsabilidad adulta.

Se abordan las dimensiones ética, estética y política como facetas del juego que, sin desconocer otras posibles, permiten hacer foco en las tensiones que se generan en el ámbito de las relaciones interpersonales entre la historia y la posibilidad de cambio (ética), el estado disposicional que caracteriza el estar y decirse jugando (estética), y las acciones tendientes a facilitar las condiciones físico ambientales y simbólicas para que el juego acontezca (política).

\section{a. Derechos de protección: rastros para la dimensión ética del juego}

Asociado al hecho de amparar, favorecer, defender, el término protección remite a la acción de alguien sobre un otro que se expone, de aquí su conexión con la idea de resguardo frente a un peligro o perjuicio. Alguien decide proteger aquello que considera digno de ser guardado, cuidado, de modo que, entre protector y protegido se establece una asimetría marcada por un juicio de valor, toma de decisión $\mathrm{y}$ acción del primero, $\mathrm{y}$ cierta vulnerabilidad, exposición y recepción del segundo. 
En este sentido, la infancia (y ya en el vocablo utilizado para nombrarla, para darle existencia como lo 'sin habla', refleja una falta, una ausencia, una negación ${ }^{4}$ ), es reconocida por el mundo adulto como una etapa vulnerable, que necesita la acción de quienes han transitado experiencias de mundo, de vida, de realidad. Ha sido la intención de proteger a la infancia de los abusos del mundo adulto la que ha impulsado en 1989 la declaración de sus derechos. Sin embargo, no se puede desconocer que en el proceso de socialización, se corre el riesgo de acallar la potencialidad de creación e innovación de las nuevas generaciones. En este dilema se asientan los rastros de la dimensión ética del juego.

Allí donde hay incertidumbre, el adulto tiende a fundar orden. En este sentido, los adultos preocupados por la infancia suelen impulsar propuestas en las que el juego aparece como instancia propicia para la incorporación de saberes sobre los que se asientan acuerdos sociales (enseñar valores, pautas de convivencia, saberes técnicos especializados como suma, resta, leer, escribir). Es así, como la dimensión ética del juego reverdece las discusiones alrededor de su uso en tanto instancia favorecedora de socialización.

Se refuerza aquí la idea de regla, en tanto 'regla regulativa' (Searle, 2007) es decir, aquella que instala el límite entre lo esperado y lo inesperado, lo permitido y lo prohibido, lo aprobado y lo sancionado, siempre desde la lógica adultocéntrica. Desde esta lectura, los niños tienen derecho a acceder a una trama de sentido cultural históricamente sedimentado, y es la educación la encargada de inculcar en los niños respeto por su identidad cultural.

Ahora bien, "la in-fancia habla más allá del lenguaje que la nombra (...) La poesía, la música, el juego (...) nos permiten escapar de una mirada tradicional que cree que la infancia es una experiencia muda cuando en todo caso es una experiencia enmudecida" (Conforte en Osella et al, 2010: 83-84).

El juego aparece entonces como un modo de expresión genuino de la infancia, es decir, de aquel que aún se resiste a los caprichos de un mundo ya construido que le exige

\footnotetext{
${ }^{4}$ Dice Agamben: "Una experiencia originaria... no podría ser entonces sino aquello que en el hombre está antes del sujeto, es decir, del lenguaje: una experiencia muda en el sentido literal del término, una in-fancia del hombre, cuyo límite el lenguaje debería señalar" (2004: 64).
} 
adaptación. El juego aparece entonces como la potencialidad del impulso creador de cultura 5 .

Si la infancia es la posibilidad de renovación del mundo y discontinuidad de un tiempo previsible, es lo inesperado que irrumpe toda expectativa (Arendt, 2005), entonces el adulto debería abandonar su lugar de 'sujeto de la apropiación', que en términos de Larrosa es "aquel que devora todo lo que encuentra convirtiéndolo en algo a su medida", para asumirse 'sujeto de la experiencia' que "sabe enfrentar lo otro en tanto que otro y está dispuesto a perder pie y dejarse tumbar y arrastrar por lo que le sale al encuentro"(2005: 178).

Allí donde hay incertidumbre, el adulto puede dejarse arrastrar para refundar un nuevo orden (quizás tremendamente desorganizado), al menos el adulto que pretende invitar a jugar a los niños desde el lugar de jugador experto (Nella Cit. en Pavía, 2010). En este sentido, los adultos preocupados por la infancia pueden impulsar propuestas en las que el juego aparezca como oportunidad para sorprender, desafiar, transgredir, imprimir recuerdos de buenas experiencias. Es así, como la dimensión ética del juego puede leerse en tanto espacio de fundación de una nueva ética.

Cuando se juega de un modo lúdico, las dicotomías entre lo bueno y lo malo, lo esperado y lo inesperado, realidad y apariencia, persona y personaje se desvanecen (pero no desaparecen, están ahí, recordándonos todo el tiempo que 'esto es un juego'), al igual que los criterios acostumbrados para establecer las diferencias. Cuando se juega de un modo lúdico, se refuerza la idea de libertad, de posibilidad, en tanto 'regla constitutiva' (Searle, 2007) es decir, aquella que instala la posibilidad del cambio, de la sorpresa, de la imprevisibilidad.

\section{b. Derechos de participación: rastros para la dimensión estética del juego}

La participación remite a la idea de ser parte, recibir una parte, de compartir, tener las mismas opiniones o ideas que las otras personas. Para jugar no basta estar con otros. Jugar implica hacer, moverse, decir, compartir, conformar, construir, armar, crear. El juego es un

\footnotetext{
${ }^{5}$ De esta sospecha parte Huizinga para instalar su tesis: el juego es más viejo que la cultura.
} 
modelo para armar, y los jugadores quienes deciden (no es casual que Cortázar haya llamado Rayuela a la particular 'novela', publicada en 1963, de múltiples finales a elección del lector).

El juego ofrece a los jugadores la oportunidad de engarzar movimientos, gestos, palabras, canciones conocidas e instaladas (que hacen que, por ejemplo, una mancha se parezca a una mancha) con acciones innovadoras que sorprenden al grupo, que cambian el rumbo a la situación. Son las acciones conocidas las que permitirían reconocer distintos juegos, y distinguir la escondida, de la mancha, el martin pescador, el tejo, o la payana. Son las acciones innovadoras y/o creativas las que hacen de cada situación de juego una versión distinta de ese juego (así, la payana que jugamos hoy no resultó igual a la de ayer). Esto es porque al jugar, las niñas y niños comparten con otros sus gustos y preferencias, ponen sus habilidades al servicio de los demás para construir juntos el juego. De aquí que, aun cuando los jugadores sean los mismos y jueguen a lo mismo, cada situación de juego sea única e irrepetible.

En la discusión sobre quienes están jugando y cómo es que consiguen entenderse en la referencia aun cuando dicen una cosa y quieren decir otra ${ }^{6}$, se asientan los rastros de la dimensión estética del juego como derecho de la infancia.

Para analizar la dimensión estética del juego como un derecho de la infancia es necesario abandonar la perspectiva utilitaria del adulto $^{7} \mathrm{y}$ asumir la de los jugadores, pues quien observa el juego puede reconocerlo opuesto a lo serio, mientras que para quien juega, el juego es muy serio.

\footnotetext{
${ }^{6}$ Por ejemplo, mientras 'están jugando' los niños dicen 'pido gancho', pero quieren decir: pido permiso a mis compañeros para desengancharme de la realidad aparente que estamos construyendo para atender a algo de la vida cotidiana (como ir al baño, tomar agua, etc).

${ }^{7}$ Cuando se observa el juego desde el lugar construido como adulto, la mirada se construye desde afuera, prevalecen las pretensiones de incidir en los niños, y desde el lugar de padre, abuelo, docente, médico, etc., conducir, guiar, tutelar, educar su desempeño. Ha sido mirando el juego infantil bajo los lentes construidos por el adulto como se le reconoce utilidad (para la construcción de aprendizajes, o para favorecer el desarrollo físico, mental, emocional y social, por ejemplo), pues quien juega no piensa en lo útil que pueda resultar, quien juega lo hace porque sí, porque gusta, divierte, entretiene. Quienes buscan utilidad al juego, lo usan como un recurso didáctico (Kishimoto, 1998; Brougere, 1998), terapéutico (Terr, 2000); "Abordan el fenómeno del juego con los métodos de mensura de la ciencia experimental, sin dedicar antes su atención la peculiaridad del juego, profundamente enraizada en lo estético. Por lo general, no se describe la cualidad primaria "juego"' (Huizinga, 2000: 13).
} 
Cuando se juega de un modo lúdico, el juego deviene una construcción estética, porque es el resultado de la relación que los jugadores establecen con la actividad (en el caso de los juegos motores), con un objeto (en el caso de los juegos con juguetes, naipes, dados) o con un artefacto (en el caso de los juegos de plaza, tableros, rodados).

Las relaciones entre los jugadores que juegan de un modo lúdico se basan en el entendimiento $^{8}$ y el poder está distribuido entre los participantes 9 .

Lo lúdico del juego ocurre si los jugadores reconocen estar jugando (y no haciendo otra cosa). Ese reconocimiento esta atravesado por un conocimiento de fondo socialmente construido, arrastrado y renovado en las prácticas cotidianas. Aprender a jugar de un modo lúdico requiere de alguien que lo enseñe, alguien que asuma la perspectiva de los jugadores, es decir, que sea jugador (Díaz cit. en Pavía, 2010), requiere de un experto en juego que juegue.

Un experto en juego sabe cuándo, cómo y por qué intervenir en el juego. Con respecto al cuándo se puede decir que interviene en dos momentos asociados al estar jugando: para generar el clima de juego (montar lo lúdico) y para sostener la tensión del juego (mantener la diversión) (Rivero, 2012). Con respecto al cómo intervenir dependerá de cada situación, y será el bagaje de experiencias lúdicas previas las que constituyen un conocimiento de fondo que le permiten al jugador resolver situaciones nuevas tomando decisiones pertinentes. Al buscar argumentos que sostengan el por qué intervenir gana nitidez el contexto social en que el jugar acontece. Aquí las dimensiones ética y política se descubren imbricadas en estética de los juegos.

\footnotetext{
${ }^{8}$ Dos cuestiones serán centrales para que los jugadores consigan entenderse: las reglas del juego que habilita el acuerdo inicial para poder jugar, es decir, estar en regla, respetando la regla (como proposición, como enunciado); y una regularidad en las intenciones, emociones y creencias compartidas por los jugadores que les permite tomarse lo que están haciendo y diciendo de mentiritas, como un juego, es decir, estar por regla jugando. Las reglas del juego acercan la dimensión política a la dimensión ética del juego. Las regularidades acercan la dimensión política la dimensión estética del juego.

${ }^{9} \mathrm{Si}$ el juego se construye a partir del aporte de los participantes, entonces todos tienen la posibilidad de intervenir cambiando el curso de juego, incluso de cambiar de rol durante el juego. Esta flexibilidad habla de un posicionamiento político diametralmente opuesto al liderazgo y la competitividad, baluartes del neoliberalismo.
} 
Para invitar a jugar el jugador experto pone su cuerpo al servicio de la invitación, se mueve para despegarse de la realidad, para desprender el sentido habitual de las acciones e intenta sorprender o desafiar a los demás. Esto obliga a pensar en qué hacer para sorprender y/o desafiar a estos niños y niñas, en estas condiciones, en este momento y en este lugar. El experto en juego opera un "corrimiento" del rol habitual (Díaz Cit. en Pavía, 2006).

La sorpresa se consigue haciendo o diciendo algo que trasciende lo esperado, que descoloca al otro, le ayuda a alejarse de la realidad, le tiende una mano para desprenderse del mundo habitual, y esto provoca risa. El desafío instala la sospecha de ser capaz, de ser competente en la habilidad, provoca al otro, le insta a mostrar y mostrarse que puede hacer aquello a lo que se le invita, y esto genera emulación que con frecuencia se acompaña de gritos.

Una vez que han montado la situación de juego, el esfuerzo se concentra en sostener la tensión del juego (oscilación entre la diversión y el aburrimiento), buscando elevar los niveles de diversión y evitando caer en el aburrimiento. El esfuerzo se concentra en mantener entre todos la realidad aparente que han creado. Para ello se ponen en marcha acciones que, sin ser acordadas entre los jugadores, son permitidas por el grupo, son bienvenidas y hasta a veces festejadas. Los gritos de aliento, las propuestas de cambio, las transgresiones.

En tanto acción de las personas involucradas, el jugar arrastra decisiones que aunque personales poseen una densa carga comunitaria, decisiones únicas e irrepetibles que intuitivamente se aprenden a tomar para sostener el sesgo de incertidumbre, de desconocimiento y de imprevisibilidad que caracteriza la acción como estar jugando (y no haciendo otra cosa, como trabajar, competir o pelear).

La incongruencia en la referencia de las acciones que llevan al desentendimiento entre las personas, al desmembramiento del movedizo límite entre estar jugando y estar haciendo otra cosa (peleando, compitiendo, pegando), instalan la sospecha de que no todas las personas tienen la posibilidad de aprender en sus entornos cotidianos a jugar de un modo lúdico. 
c. Derechos de provisión: rastros para la dimensión política del juego

El concepto provisión encierra la idea de obtener lo necesario para conseguir un fin. Si el fin es jugar, entonces se piensa en las condiciones y disposiciones necesarias para que el juego infantil acontezca.

En la primera acepción del término, provisión remite a la acción de preparar o reunir, de modo que, quien provee lo necesario tiene previsto participar, se compromete en el fin pero no lo direcciona. Provisión sería sinónimo de providencia, disposición, arreglo. En la segunda acepción del término, provisión remite a la idea de suministrar o facilitar, de modo que, el proveedor de lo necesario trabaja para atender lo que puede anticipar que se va a necesitar, establece una relación asimétrica respecto de un receptor. Aquí provisión sería sinónimo de suministro o abastecimiento.

Partiendo de la idea de provisión en tanto providencia, disposición o arreglo para pensar la atención del derecho a jugar, se pueden identifican, por un lado, a las organizaciones que preparan y ponen a disposición las condiciones físicas, ambientales y materiales para que las niñas y niños puedan jugar; por el otro lado, a los jugadores que preparan y ponen a disposición las condiciones simbólicas para poder jugar.

Partiendo de la idea de provisión en tanto suministro o abastecimiento para pensar la atención del derecho a jugar, se pueden identificar acciones de diferentes actores de la sociedad, que configurarían la dimensión política del juego.

En el suministro de condiciones físicas, ambientales, materiales y simbólicas para jugar, se pueden reconocer a actores externos al juego que pueden percibir la importancia de promover y garantizar experiencias de juego en las niñas y niños, y deciden actuar en consecuencia.

En este sentido, se pueden identificar padres, docentes, médicos, psicólogos, directores de escuelas, de clubes, de empresas, organizaciones no gubernamentales, fundaciones, y otras agrupaciones que gestionan el reconocimiento del derecho de las niñas y niños al juego. Identifican temas de vacancia, problemáticas y necesidades, instalan 
discusiones, impulsan iniciativas, formalizan pedidos, elaboran propuestas, trabajan en la prevención y atención, se esfuerzan por posicionar temáticas en la agenda gubernamental.

También se identifican actores que asumen la responsabilidad de tomar decisiones para favorecer la disposición, apropiación y mantenimiento del espacio público destinado a jugar, ya sean plazas, parques, ludotecas barriales, vecinales. Así, se pueden reconocer equipos de gestión barrial, vecinal, municipal, sectorial que ponen (o debieran) poner a disposición de la sociedad oportunidades y condiciones en atención del derecho de las niñas y niños al juego.

Repasando algunos organismos internacionales que trabajan favoreciendo la instalación del juego en niñas, niños y adolescentes en la agenda de las preocupaciones sociales se pueden mencionar a UNICEF, Fondo de las Nacional Unidas para la Infancia, que vela por el cumplimiento de la Convención sobre los Derechos del Niño; a la UNESCO, Organización de las Naciones Unidas para la Educación, la Ciencia y la Cultura; el Instituto Interamericano del Niño, la Niña y Adolescente (organismo especializado de la Organización de Estados Americanos- OEA), Organización de Estados Iberoamericanos para la Educación, la Ciencia y la Cultura (OEI), el Programa Internacional para la Erradicación del Trabajo Infantil de la Organización Internacional del Trabajo (OIT), el Sistema de Información sobre la Primera Infancia en América Latina (SIPI), Save the Children, Red de Información sobre Derechos del Niño, la Organización Mundial de Educación Prescolar (OMEP), entre otras.

Estos organismos asumen el compromiso de esforzarse en la obtención de las condiciones necesarias para que las niñas y niños puedan ejercer sus derechos ${ }^{10}$. Cabe entonces preguntarse, ¿a qué da derecho el derecho al juego?.

\footnotetext{
${ }^{10}$ Aquí habrá que aclarar que mientras algunos de los organismos mencionados les corresponde asumir la responsabilidad de poner a disposición de la sociedad las condiciones necesarias que hagan efectivo el ejercicio de los derechos de la infancia porque han sido elegidos por la voluntad popular para ello; otros organismo en cambio, deciden voluntariamente trabajar en la misma dirección. Mientras los organismos gubernamentales sufren un alta rotación de personas a cargo (pues depende de los grupos que asumen políticamente los espacios), los organismos no gubernamentales, asociaciones y fundaciones tienden a sostener por más tiempo la permanencia de las personas comprometidas.
} 
En principio, el disponer de espacios públicos preparados para el esparcimiento, espacios al aire libre, pensados, diseñados, cuidados, mantenidos. Espejos de agua, parques, paseos, lugares que favorezcan el encuentro y la integración entre personas, lugares para que todas las personas puedan disfrutarlo. Espacios a los que se pueda acceder sin dificultades, que estén dotados de artefactos y equipamiento que puedan ser utilizados por todos. Espacios públicos destinados al esparcimiento que hay que diseñarlos pensando en los usuarios, hacerlos destinando los fondos necesarios para que resulte una obra de calidad, y mantenerlos invirtiendo en la paga de personas dedicadas a su cuidado, y al arreglo y reposición de materiales deteriorados.

El derecho al juego también da derecho a disponer de una ciudad accesible, que todos puedan aprovecharla y utilizarla (Tonucci Cit. en Anteló et al, 2009). Una ciudad natural, con árboles, arbustos, lomas, tierra, pasto, plantas, cuidada por todos, de la que todos nos sintamos responsables. Una ciudad que ponga a las personas en contacto con la naturaleza, que permita apreciar la sombra de un árbol, el sonido de los pájaros que encuentran refugio en él, o sentir el viento en la cara; una ciudad con espacios que inviten al movimiento corporal y que resguarde a quien lo usa. Contar con una ciudad saludable no sólo es responsabilidad de los organismos gubernamentales y no gubernamentales, sino de todos. El trabajo de estos organismos se ve potenciado por el trabajo minucioso de la familia, la escuela, el club, entre otras instituciones sociales que contribuyen a dar forma a acciones cotidianas que hacen efectiva (o no) la defensa y promoción de los derechos.

El derecho a jugar da derecho a contar con personas que enseñen a confiar en sí mismo y en los demás, y a compartir con otros. Propiciar el encuentro entre niñas y niños, dejar montar el escenario para jugar (montaje que suele presentarse como desorden para la estructuración adulta), poner a disposición elementos atractivos que oficien de juguetes, acompañar a los niños (no para controlarlos sino para ofrecerles confianza), aceptar momentos de gritos, risas, corridas, expresiones genuinas del juego infantil que desarticulan la lógica adulta, serían acciones esperadas en los adultos a cargo de niñas y niños. Tolerancia, paciencia, sensibilidad condiciones simbólicas necesarias para que los niños ejerzan su derecho al juego en el marco de una vida saludable. 


\section{A modo de cierre}

Un escrito sobre el derecho de las niñas y niños al juego en Argentina no resulta una novedad en los días que corren. Sin embargo, la infancia, los derechos humanos, la igualdad de género, la discapacidad, la tercera edad, son temas que han ido instalándose en la agenda de preocupaciones sociales en un proceso lento pero continuo, facilitado por la consideración de la opinión experta de quienes transitan el territorio (Organizaciones No Gubernamentales, Fundaciones) en el rumbo de las decisiones gubernamentales.

La Convención sobre los Derechos del Niño sancionada en 1989 hizo un aporte decisivo en la visualización de la infancia en el ámbito público. Al reconocer a las niñas y niños en tanto sujetos de derecho, este documento internacional dio inicio a un proceso de transformación en el modo de ver, entender y atender a la infancia ${ }^{11}$.

La adhesión de Argentina a la Convención sobre los Derechos del Niño hacia fines de 1990, meses después de ser sancionada, marca entonces una inflexión, una transformación que implicó pasar de entender a las niñas y niños como menores, a entenderlos como sujetos de derecho. De un Estado que asumía la patria potestad de los menores en riesgo, se pasó a un Estado comprometido en asegurar al niño la protección y el cuidado necesarios para su bienestar, teniendo en cuenta los derechos y deberes de sus padres o tutores. La consideración de las niñas y niños en su contexto familiar y comunitario refuerza la preservación de la identidad cultural, de las costumbres locales, entre ellas los juegos populares y tradicionales, cuyas dinámicas, cantos, juguetes están incorporados en la vida cotidiana de la comunidad y transparentan formas de vida.

El cambio de paradigma se fue dando paulatinamente. El Comité Argentino de Seguimiento y Aplicación de la Convención Internacional sobre los Derechos del Niño (CASACIDN) ha sostenido la presencia de la temática en distintas mesas de discusión. Esta

\footnotetext{
${ }^{11}$ Desde 1919 y hasta ese momento regía en Argentina la Ley de Patronato de Menores en atención a los niños y niñas en situación de abandono material o peligro moral. Así, esta ley consideraba a los niños y niñas en situación de material o peligro moral menores en riesgo y el Estado debía protegerlos. Para este fin, la ley llevó a instrumentar la separación de los niños del seno familiar para tutelarlos en institutos, tendiendo a "patologizar situaciones de origen estructural... convertían en irregular al niño y a su familia en vez de ver la irregularidad en la falta de oportunidades” (Mauras en Aguilar, Astudillo y Calzón Fernandez, 2012: 283).
} 
coalición de organizaciones de la sociedad civil, nacida en 1991, ha representado al país en múltiples actuaciones internacionales y ha impulsado acciones valiosas que han dado por resultado la ley 23.849 que aprueba la Convención de los Derechos del Niño, la incorporación de la Convención en la reforma de 1994 de la Constitución Nacional ${ }^{12}$, y la sanción de la Ley de Protección Integral de los Derechos de las Niñas, Niños y Adolescentes (Ley 26.061) en 2005.

La ley de Protección Integral de los Derechos refiere a las niñas, niños y adolescentes. En ese acto distingue niñez de adolescencia y da entidad al género femenino (incluso instala la costumbre de nombrarlo primero), discusión ausente hasta entonces y tema sensible en esta sociedad.

El artículo 20 de la Ley de Protección Integral de los Derechos de las Niñas, Niños y Adolescentes, está destinado al derecho al deporte y juego recreativo. Dicho artículo reza que "los Organismos del Estado con la activa participación de la sociedad, deben establecer programas que garanticen el derecho de todas las niñas, niños y adolescentes a la recreación, esparcimiento, juegos recreativos y deportes, debiendo asegurar programas específicos para aquellos con capacidades especiales".

Así, en Argentina el juego es un derecho de las niñas, niños y adolescentes; derecho que puede hacerse extensible a los sujetos de derecho cuando de esparcimiento, recreación, deporte, educación se trata ${ }^{13}$.

${ }^{12}$ El artículo 75 de la Constitución Nacional de la República Argentina, declara que le corresponde al Congreso aprobar o desechar tratados internacionales que tienen jerarquía superior a las leyes. Entre esos tratados nombra a la Convención sobre los Derechos del Niño, hecho que no sólo orienta políticas públicas en atención a niñas y niños sino que se asigna financiamiento público a tal fin.

${ }^{13}$ A continuación dos ejemplos en donde el juego no tarda en aparecer.

- El artículo III de la Convención de Interamericana para la Eliminación de todas las Formas de Discriminación contra las Personas con Discapacidad, declara el compromiso del Estado en tomar medidas para eliminar progresivamente la discriminación y promover la integración por parte de las autoridades gubernamentales y/o entidades privadas en la prestación o suministro de bienes, servicios, instalaciones, programas y actividades, tales como la recreación, la educación, el deporte, entre otros.

- El Artículo 22 de la Convención Interamericana sobre la Protección de los Derechos Humanos de las Personas Mayores establece que "La persona mayor tiene derecho a la recreación, la actividad física, el esparcimiento y el deporte. Los Estados Parte promoverán el desarrollo de servicios y programas de recreación, incluido el turismo, así como actividades de esparcimiento y deportivas que tengan en cuenta los intereses y las necesidades de la persona mayor, en particular de aquella que recibe servicios 
Más allá de su presencia y/o mención en los derechos humanos, si se garantizan los derechos de las niñas y niños, las ciudades se vuelven más accesibles para todos (Tonucci, 2015).

Pese a estos avances, el Comité de los Derechos del Niño, formuló en el año 2013 la observación 17 donde expresa su preocupación por el escaso reconocimiento que los Estados otorgan a los derechos contenidos en el artículo 31; que se traduce en la ausencia de inversiones en disposiciones adecuadas, una legislación protectora débil o inexistente y la invisibilidad de los niños en la planificación a nivel nacional y local.

En este sentido, en una investigación que estudia la infancia en Argentina entre 1983 y 2001, Carli afirma que:

"El período analizado, caracterizado por la estabilidad de la democracia como sistema de gobierno, expresa a su vez la escisión creciente entre el sentido social de la democracia política y el bienestar infantil, en tanto priman los modos de globalización de la noción de infancia y de individualización de las intervenciones colectivas que evitan una indagación de las consecuencias sociales sobre la niñez del empobrecimiento notorio de la sociedad argentina... En el período analizado la infancia devino en signo... a la vez que las condiciones de existencia de la población infantil en Argentina presentaron los peores indicadores del siglo XX" (2016: 48).

El Comité también expresa preocupación por las dificultades con las que tropiezan algunas categorías de niños (niñas, niños pobres, discapacitados, indígenas o que integran una minoría) para el ejercicio de dicho derecho. En este sentido, se vuelve una necesidad revisar la relación entre el derecho de los niños al juego y los derechos a la no discriminación, y la identidad cultural.

Los diversos contextos en que acontece la cotidianeidad de las niñas y niños van trazando una heterogeneidad imposible de apresar en la referencia (de algún modo uniformante) de las niñas y niños. Nota no menor será que esta cuestión dificulta la representación política de la niñez (Eberhardt Cit. en Carli, 2006). 
Más allá de las diversas formas de transitar la infancia, el juego es un universal cultural que tiene primacía en la infancia de la historia del hombre (Tonucci, 2015). Entender el juego como actividad es poner la lente sobre la dimensión estructural de la actividad que la comunidad reconoce como juegos, y conlleva al planteo ético de lo que significa jugar bien. Es responsabilidad de los adultos facilitar un amplio repertorio de juegos locales, regionales, tradicionales, interculturales adecuados a la edad de los niños y al contexto inmediato. Juegos sencillos y complejos, populares y tradicionales, cooperativos y deportivos, juegos de construcción, de azar, de mímica, juegos de vértigo, de emulación, juegos suaves y violentos, bulliciosos y tranquilos, juegos de ronda, de persecución, de tablero, con pelotas, con paletas, juegos individuales y colectivos.

El juego es una acción colectiva, implica a otro que comparte el sentido, se vuelve compañero, cómplice, aun cuando opere de contrincante. El juego es una situación que se construye y se sostiene entre quienes deciden disfrutar de esa construcción. Es hacer, decir, sentir, creer y hacer creer 'de mentiritas', es construir una manera de ser y estar diferente a la habitual. De aquí que actividades sencillas como remontar un barrilete, caminar por una cuerda floja o por el cordón de la vereda, el andar en bicicleta, corretear, armar un collage entre todos, interpretar canciones, sean dichas un juego aun cuando su formato no sea identificado como tal. En esta dirección, el juego es de los jugadores, armado, discutido y consensuado por ellos, por ello se vuelve necesario propiciar lugares y condiciones para desarrollar la autonomía lúdica. Entender el juego como acción es poner la lente sobre la dimensión cultural incorporada por los jugadores, que conlleva al planteo estético. En este sentido, habrá que estar alerta de la neutralización de experiencias de diferentes sectores de la población infantil (niñas, discapacitados, aborígenes, rurales) que propone la oferta de signos universales en las producciones visuales.

El juego es un artefacto cuyo uso no es unilateral, sino que invita a ser utilizado creativamente. Un juego es también un aparato que llaman al movimiento corporal, a la exploración, al encuentro con el otro, a vivir sensaciones diferentes, a hacer algo distinto. De aquí que se llamen juego a los trepadores, hamacas, toboganes, canchas, pistas, tableros, mesas, calecitas, dados, rompecabezas, y también a los juguetes, como muñecas, autitos, 
trompos, valeros, yo-yos, bolitas. Entender el juego como artefacto es poner la lente sobre la dimensión socio-política del juego, que conlleva al planteo de lo que significa ser niño y jugar en los tiempos que corren. Tiempos en que han comenzado a escasear las opciones particulares. La oportunidad de optar no acontece aislada de un contexto político. En este sentido, la publicidad no solo proporciona productos sino que modela al niño que consume (Minzi Cit. en Carli, 2015).

Si bien el impacto del advenimiento de los medios electrónicos define la impronta principal de esta realidad de la que no hay retorno, no les llega a todos por igual. No toda la infancia, como un bloque monolítico, participa de las bondades y los riesgos que la era de los medios electrónicos supone. Las desigualdades sociales destacadas a partir de las opciones para jugar, demandan una intervención efectiva a nivel de las diferentes instancias de los estados nacional, provincial y municipal, y de los ciudadanos en general. "Los niños a la escuela y a jugar, pero no como opciones sino como derechos" (Centurión, inédito), de los cuales los adultos debemos constituirnos en celosos custodios para que les llegue a todos los niños sin excepción.

Reconocer que las niñas y niños tienen derechos humanos sólo es posible en un contexto donde la democracia tiene vigencia total, donde la infancia puede expresar con plenitud sus derechos, entre ellos el derecho a jugar. Revisar los tiempos, momentos, escenarios, las condiciones materiales y simbólicas en que el juego de las niñas y niños de contextos diversos acontece se vuelve un desafío.

Somos los padres, abuelos, tíos, vecinos, maestros, los que tenemos que velar ya no sólo por la ausencia de enfermedad de las niñas y niños, sino actuar en la inmediatez de lo próximo y cotidiano para hacer un aporte a la garantía de sus derechos.

Para crecer sanos y felices, las niñas y niños necesitan vivir en una vivienda digna, alimentarse adecuadamente, y contar con atención en estado de enfermedad; necesitan también ser amados, estar insertos en una trama cultural, acceder a la educación, contar con la posibilidad de reunirse y compartir con otros, necesitan descansar, esparcirse, jugar. 
No olvidar: el juego es un derecho de los niños que los adultos (padres, docentes, médicos, psicólogos, directores de escuelas, de clubes, de empresas, organizaciones no gubernamentales, fundaciones y demás agrupaciones) tenemos la obligación de garantizar identificando temas de vacancia, problemáticas y necesidades, instalado discusiones, impulsando iniciativas, formalizando pedidos, elaborando propuestas, trabajando en prevención y atención, esforzándose en posicionar temáticas en la agenda gubernamental.

El escrito que aquí se comparte surgió a solicitud de una fundación argentina (con presencia en Chile y Brasil) que atiende a problemáticas de la infancia. Su solicitud deja en evidencia que las organizaciones no gubernamentales ponen alas, echan a volar y cuidan el vuelo de palabras, de ideas, para impactar en la vida cotidiana de las niñas y niños. Y al reverso, piden palabras que nombren la realidad, que muestren su complejidad, sus tonalidades; palabras que sacudan la realidad, que ayuden a pensar, a transformar. Si el nombrar da existencia a las cosas (Habermas, 1990), si con las palabras se hacen cosas (Austin, 1982) entonces las organizaciones no gubernamentales dan existencia a la infancia, al juego. los hacen visibles y generan compromiso.

\section{Referencias bibliográficas}

AAVV, (1996). El juego, necesidad, arte, derecho. Asociación Internacional por el Derecho del Niño a Jugar. Bonum. Buenos Aires.

Agamben, G. (2004). Infancia e Historia. Destrucción de la experiencia y origen de la historia. Adriana Hidalgo. Buenos Aires.

Aguilar, M.; S. Astudillo y Y. Calzón Fernandez (2012) ¿Qué es esto de los derechos humanos? : Apuntes para una reflexión crítica: historias, documentos conceptos y actividades. Instituto Espacio para la Memoria. Buenos Aires

Antelo, E.; A. Abramowski; y M. Arruabarrena. "Entrevista a Francesco Tonucci. La ciudad es hostil porque hecha a los niños de los espacios públicos”. En cursiva. Revista temática sobre infancia y educación. Espacios que educan. Año 3. Nro 5. Junio de 2009.

Arendt, H. (2005). La condición humana. Paidós. Buenos Aires. 
Austin, J. (1982). Cómo hacer cosas con palabras: Palabras y acciones. Paidós. Barcelona.

Brougere, G. (1998). Jogo e educação. Artes médicas. Porto Alegre.

Caillois, R. (1994). Los juegos y los hombres. La máscara y el vértigo. Fondo de cultura económica. México. 1958.

Carli, S. (Comp.) (2016). La cuestión de la infancia. Entre la escuela, la calle y el shopping. Paidós. Buenos Aires.

Centurión, S. (2013). Juego e infancia en tiempos de los medios electrónicos. Inédito.

Dewey, J. (2008). El arte como experiencia. Paidós. Buenos Aires.

Elías, N. y E. Dunning. (1992). Deporte y ocio en el proceso de socialización. Fondo de cultura económica. Buenos Aires.

Gadamer, H. (2005). La actualidad de lo bello. Buenos Aires: Paidós.

Habermas, J. (1990). Pensamiento postmetafisico. Taurus. Buenos Aires.

Huizinga, J. (2000). Homo Ludens. Madrid: Alianza. 1938.

Kishimoto, T. (1998). Jogos infantis. O jogo, a crianca e a educacao. Petropolis: Voces.

Larrosa, J. (2000). Pedagogía profana. Estudios sobre lenguaje, subjetividad, formación. Novedades educativas. Buenos Aires.

Lester, S. y W. Russell. (2011). El derecho de los niños y las niñas a jugar. Análisis de la importancia del juego en las vidas de niños y niñas de todo el mundo. Cuadernos sobre Desarrollo Infantil Temprano 57s. La Haya, Países Bajos. Fundación Bernard Van Leer.

Mandoki, K. (2006). Estética cotidiana y juegos de la cultura. México. Siglo XXI.

Mantilla, L. (2001). Juego y jugar, ¿un camino lineal y sin retorno? Estudios sobre las culturas contemporáneas, 100-123.

Naishtat, F. (2005). Problemas filosóficos en la acción individual y colectiva: Una perspectiva desde la pragmática. Prometeo. Buenos Aires. 
Osella, M.; M. Moretti; P. Olmedo; M. Bedano. (Comp.) (2010). Filosofía e Infancia. El lugar de la infancia en la filosofía y en la educación. Actas II Coloquio Nacional de. Filosofía Río Cuarto. Unirío. Río Cuarto.

Pavía, V. (Coord.) (2006). Jugar de un modo lúdico. El juego desde la perspectiva del jugador. Edicial. Buenos Aires.

Pavía, V. (Coord.) (2010). Formas del juego y modos de jugar. Secuencias de Actividades Lúdicas. Educo. Editorial de la Universidad Nacional del Comahue. Neuquén.

Pellegrinelli, D. (2000). “Juegos, juguetes e infancia”. En En Cursiva, Año 4, No 6. Agosto de 2010. Pág- 44-48.

Restrepo, H. y H. Málaga. (2001). Promoción de la salud: cómo construir vida saludable. Panamericana. Bogotá.

Rivero, I. (2012). El juego desde la perspectiva de los jugadores: Una investigación para la didáctica del jugar en educación física [en línea]. Tesis de posgrado. Universidad Nacional de La Plata. Facultad de Humanidades y Ciencias de la Educación. En Memoria Académica. Disponible en: http://www.memoria.fahce.unlp.edu.ar/tesis/te.901/te.901.pdf

Sarlé, P. (2001). Juego y aprendizaje escolar. Los rasgos del juego en la educación infantil. Novedades Educativas. Buenos Aires.

Scheines, G. (1998). Juegos inocentes, juegos terribles. Eudeba. Buenos Aires.

Searle, J. (2007). Actos de habla. Ensayos de filosofía del lenguaje. Cátedra. Madrid. 1980.

Tonucci, F. (2015). La ciudad de los niños. Grao. Barcelona.

Wittgenstein, L. (2004). Investigaciones filosóficas. Crítica. Barcelona.

Documentos

Convención sobre los Derechos del Niño. Adoptada y abierta a la firma y ratificación por la Asamblea General en su resolución 44/25, de 20 de noviembre de 1989. En 
UNICEF, 2014. La Convención sobre los Derechos y sus tres Protocolos Facultativos. UNICEF. Buenos Aires.

Ley de Protección Integral de los Derechos de las Niñas, Niños y Adolescentes. Ley 26.061, sancionada en 2005. www.unicef.org/argentina.

Comité de los Derechos del Niño. Observación general No 17 (2013) sobre el derecho del niño al descanso, el esparcimiento, el juego, las actividades recreativas, la vida cultural y las artes (artículo 31). www.unicef.org. 